\title{
Ciliated protozoa in the impact zone of the Uzhgorod treatment plant
}

\author{
Volodimir Pliashechnyk ${ }^{1}$, Yaroslav Danko ${ }^{2}$, Grzegorz Łagód ${ }^{3}$, Jakub Drewnowski $^{4}$, Tatiana \\ Kuzmina $^{5}$, and Roman Babko ${ }^{6}$ \\ ${ }^{1}$ State institution of higher education "UzhNU", Narodna Square 3, 88000 Uzhhorod, Ukraine \\ ${ }^{2}$ Sumy Makarenko State Pedagogical University, Romenska 87, 40002 Sumy, Ukraine \\ ${ }^{3}$ Lublin University of Technology, Environmental Engineering Faculty, Nadbystrzycka 40B, 20-618 \\ Lublin, Poland \\ ${ }^{4}$ Gdansk University of Technology, Civil and Environmental Engineering Faculty, Narutowicza \\ 11/12, 80-233 Gdańsk, Poland \\ ${ }^{5}$ Sumy State University, N. Rimsky-Korsakov 2, 40007 Sumy, Ukraine \\ ${ }^{6}$ Schmalhausen Institute of Zoology National Academy of Sciences of Ukraine, B. Khmelnitsky 15, \\ 01601 Kiev, Ukraine
}

\begin{abstract}
This paper presents the results of studies on the Uzh River (Ukraine, Zakarpattia Oblast) near the effluent point of a sewage treatment plant in Uzhgorod. The samples were taken at various sites of the treatment plant along the stages of purification process, as well as in the river, at a number of different points above and below the wastewater discharge. At each of these objects, the temperature and $\mathrm{O}_{2}$ were measured. The structure of ciliate assemblage was analyzed along the stages of the treatment process in the WWTP and in the river before and after the sewage discharge. A total of 26 ciliate taxa were observed and included in the analysis. All the studied stations were considered as a continuum in which populations of protozoa spread freely according to their ecological preferences. The majority of ciliate species were encountered in each of the examined stations, but their quantitative development differed significantly, reflecting their response to the environmental conditions at the stations. The analysis of the qualitative and quantitative distribution of ciliate populations by the stations enabled to group them in respect to the peculiarities of the local conditions. The study showed that the majority of the ciliate species, typical of bioreactors, are equally common at the stations of the Uzh River below wastewater discharges. The ciliate assemblage in the oxygen gradient demonstrated a wide spectrum of ecological tolerance at the species level. These findings confirm that ciliates are very good indicators of the environmental quality, provided that detailed information about their environmental priorities is available.
\end{abstract}

\section{Introduction}

In the $19^{\text {th }}$ century, many rivers in Europe which flow through settlements, received huge amounts of domestic and industrial wastewater. As a result of the industrial development and the growth of cities in the $19^{\text {th }}$ century, even large rivers such as the Rhine, the Oder, 
the Thames, the Vistula, the Seine and other European rivers were critically polluted. Creation of sewage treatment plants, enabled to prevent the final degradation of European rivers. The development of technology over the past 100 years has significantly reduced the impact of sewage. However, so far it has not been possible to eliminate their impact on hydrobionts completely. In most cases, the influent sewage locally changes the trophic status of the reservoirs [1, 2], provoking the growth of bacteria [3], protozoa and thereby providing nutritional requirements for many invertebrate species [4], which entails changes in the structure of aquatic biocenosis [5-10]. A significant negative aspect of wastewater discharge points is that they induce the effect of pollutant accumulation and decrease the resistance of the hydroecosystem [4]. For example, Madoni discovered that the Parma River at the moment of study was more polluted than ten years earlier, and its ciliate community changed dramatically [11]. Often, the sewage discharged to a river induces processes leading to a decrease of dissolved oxygen content or even local anoxia (Spänhoff, 2007, Wakelin, 2008)[3, 12]. In the context of water bodies protection, apart from the improvement of wastewater treatment quality, an important role is played by the assessment of treated water impact on natural biocenoses. The complexity of such assessments and uncertainty of their results is obvious, since systemic disturbances depend not only on the content (chemical composition) and the amount of wastewater, but also on the self-cleaning potential of natural reservoirs, their ecological plasticity and resistance to contamination. Nowadays, there are many methods for assessing the state of hydrobiocenoses, starting from an organoleptic assessment of water quality to highprecision physicochemical methods and biotesting. However, as far as assessing the quality of aquatic ecosystems is concerned, the current preferences of researchers are increasingly shifting towards the use of systemic environmental indicators, which enable to evaluate the quality of the aquatic environment as a habitat for the biocenosis. In this respect, the ciliated protozoa are used most frequently. In reservoirs, they are represented by a significant variety of species $[13,14]$ the quantitative and qualitative distribution of which reflects the reaction of biocenoses to the external influences [11, 15-18]. Although there is a considerable amount of data on the occurrence of species under different conditions, objectively, for many species, the available data concern only narrow ranges of factors. Obtaining objective data on the realization of a population in the continuum of a particular limiting factor within a natural body of water is a very difficult task. However, it is very relevant in the context of improving the methods for assessing the quality of the environment.

\section{Materials and methods}

The studies were carried out on the Uzh River (Ukraine, Zakarpattia Oblast) near the effluent point of a sewage treatment plant in Uzhgorod in January-April 2017. The samples were taken at various sites of the treatment plant along the stages of purification process, as well as in the river at a number of different points above and below the wastewater discharge. Thus, the investigated objects are of the two types. The first includes the main elements of Uzhgorod WWTP's: primary clarifier, aeration tank, secondary clarifier, mixing channel, effluent channel. On the other hand, the second comprises a fragment of Uzh river: $50 \mathrm{~m}$ upstream from wastewater discharge (uzh0), at the WWTP's discharge site, 50, 100, 250 and $300 \mathrm{~m}$ below the discharge.

At each of those objects, the measurements of temperature and $\mathrm{O}_{2}$ were conducted by means of the HACH HQ40d Portable Multi-Parameter Meter. In all of the investigated sites, samples of water were taken with a $300 \mathrm{~mL}$ syringe. On the river, the samples were taken using a syringe with a plastic tip up to $0.5 \mathrm{~m}$ long, which enabled to take a bulk sample of bottom sediments. After the sampling, the samples were immediately delivered 
to the laboratory of Uzhgorod University and processed. In order to preserve the unprocessed samples, they were kept in the refrigerator at a temperature of $+5^{\circ} \mathrm{C}$, which slowed down the degradation processes. Species identification was based on [19-23]. When necessary, cells were stained with the use of $1 \%$ methyl green or silver nitrate [30]. Estimation of population density was performed on the basis of counting organisms in subsamples of $25 \mu \mathrm{L}$ each, using a micropipette, as described by [24]. Counting was performed 5 times for each active sludge sample and 11 times for bottom sediments. Determination of the species composition and calculation of the abundance of ciliates was performed with an Olympus CX41 microscope in transmitted light. Data were processed using R version 3.4.0 [25]. Hierarchical clustering was performed with hclust from core R package stats, fuzzy clustering with fanny from cluster [26], Principle Components Analysis (PCA) with fviz_cluster from factoextra [27], Non-metric multidimensional scaling (NMDS) with metaMDS from vegan [28]. Plots were produced using R packages ggplot2 [29], factoextra [27], ggrepel [30], directlabels [31].

\section{Results and discussion}

The structure of ciliate assemblage was analyzed along the stages of treatment process in the WWTP and in the river before and after sewage discharge. The treated sewage from WWTP entered the river Uzh from the right bank. The speed of the current in the river at the discharge point varies from 1 to $2 \mathrm{~m}$ per second. The station that is not affected by effluents and can be considered as a control is located $50 \mathrm{~m}$ upstream of the wastewater discharge. Changes in the structure of ciliate assemblage in the river were monitored at distances of 50, 100, 250 and $300 \mathrm{~m}$ downstream the WWTP discharge. At all the stations on the river and in the WWTP, the water temperature ranged from 2 to $8^{\circ} \mathrm{C}$, and the concentration of dissolved oxygen was between 2 and $14.5 \mathrm{mg} \mathrm{L}^{-1}$. A total of 26 ciliate taxa were observed, 24 out of which were identified to the species level and included in the analysis. All the studied stations can be considered as a continuum in which populations of protozoa spread freely according to their ecological preferences. Considering that the ranges of organic matter content, oxygen concentration and temperature amplitude were quite wide, the development of the protozoan populations, a priori, should reflect their environmental priorities with respect to these factors. Indeed, the majority of ciliate species were encountered at all examined stations, but their quantitative development differed significantly, reflecting their response to the environmental conditions occurring at the stations. The analysis of the qualitative and quantitative distribution of ciliates populations by the stations enabled to group the stations in accordance with the peculiarities of the local conditions. The results of the cluster analysis are shown in Fig. 1.

The cluster analysis showed that the stations studied is divided into two major groups of clusters, which indirectly confirms the presence of significant structural rearrangements in the protozoan assemblages. The first group combines an aeration tank with stations on the river, located at a distance of 50, 100 and 150 meters downstream from the wastewater inlet. The second group combines primary and secondary clarifiers and derivation channel of the treatment plant with stations on the river, where the impact of the WWTP is minimal - $300 \mathrm{~m}$ downstream from wastewater discharge - and maximal - at the point of wastewater discharge. Obviously, proximity in space is not the only factor that forms these two clusters. A more significant factor than spatial proximity is the presence or absence of the activated sludge at the considered stations. The first cluster is composed of stations where the activated sludge is present; in contrast, the second one is where the sludge absent. Stations at 50-150 m downstream (belonging to the first group of clusters) are under the conditions resembling those in the aeration tank: energy subsidies in the form of organic matter from treatment plants, vigorous mixing and sufficient concentrations of dissolved 
oxygen. For obvious reasons, activated sludge is absent at most stations from the second group of clusters.

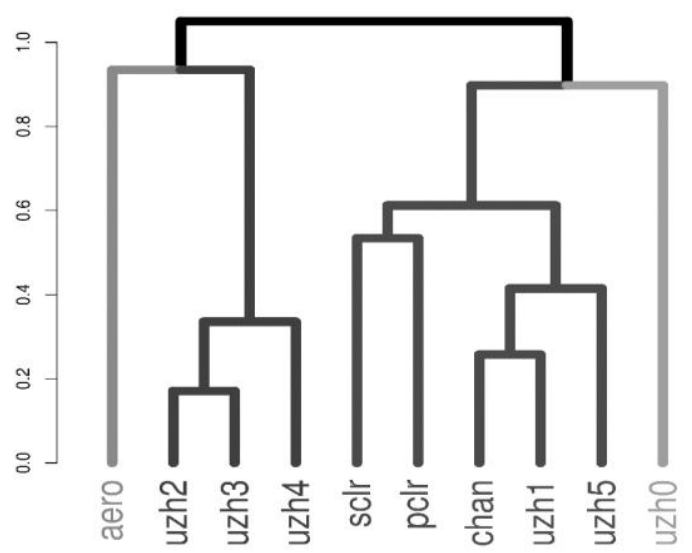

Fig. 1. Ward clustering of a matrix of Kulczynski distances among stations. Data were Hellinger transformed. Stations: aero - aeration tank, chan - derivation channel, pclr - primary clarifer, sclr - secondary clarifer, uzh0 - river $50 \mathrm{~m}$ upstream the treated wastewater discharge, uzh1 - river at the discharge site, uzh2, uzh3, uzh4, uzh5 - river 50, 100, 250 and $300 \mathrm{~m}$.

The absence of the activated sludge in the river at the wastewater inlet is explained by the specific conditions at this point, i.e. where sewage and river water meet. It can be said that under the conditions of flow, space plays the role of time and the activated sludge in the river requires a certain amount of time to form, which in this case means that it forms only at a certain distance downstream.

The considerable amplitude of the conditions realized at the considered stations enabled to observe a quantitative realization of the ciliate populations in the gradient of two important environmental factors. Our research was focused on the spatial distribution of the ciliates populations along oxygen and temperature gradients. Nonmetric multidimensional scaling was used for visualization of similarities in ciliate species composition and abundance of the studied sites.

Relative positions of the considered stations and ciliate species with oxygen gradient superimposed obtained by NMDS are presented in Fig. 2. The impact of WWTP is evident. Only site upstream of WWTP (uzh0) is clearly outside of impact. All other sites in the NMDS space are located quite close to secondary clarifier or derivation channel. The location of sites in those space correlates $\left(\mathrm{r}^{2}=0.58, \mathrm{p}<0.05\right)$ with the dissolved oxygen concentration. The results show a highly differentiated response of the infusoria species to the oxygen gradient. At the same time, some of the species, common for activated sludge, reached a maximum under the river conditions. The presence of the species under the conditions of the bioreactor (activated sludge) is not the basis for the assertion that its ecological optimum is located exactly under these conditions. However, it should be noted that in the space of the nonmetric multidimensional scaling, the species encountered in the treatment facilities most frequently — Aspididsca cicada, Plagiocampa rouxi, Acineria uncinata, Vorticella aquadulcis, etc. are closest to the station of aeration tank. On the other hand, the species that are practically not registered under the conditions of treatment plants are clearly located in this coordinate system in the area of the station not affected by effluents.

The temperature is obviously an important ecological factor; however since the studies were conducted in the winter-spring period, a sufficient amplitude for the temperature 
gradient was not obtained. The temperature gradient was directed against the oxygen gradient, but its impact was less pronounced $\left(\mathrm{r}^{2}=0.45, \mathrm{p}<0.1\right)$ Fig. 3 .

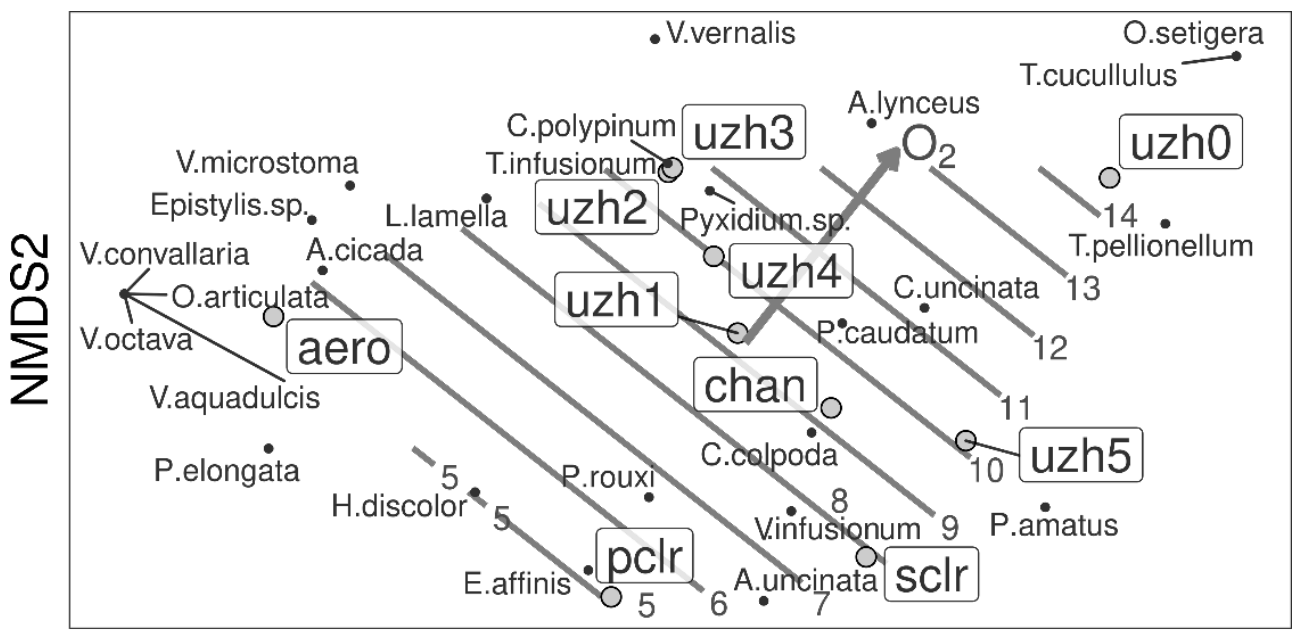

\section{NMDS1}

Fig. 2. Non-metric multidimensional scaling biplot of a Kulczynski distance matrix of Hellingertransformed data on the ciliates abundance with the gradient of dissolved oxygen superimposed. The designations of the stations are the same as in Fig. 1.

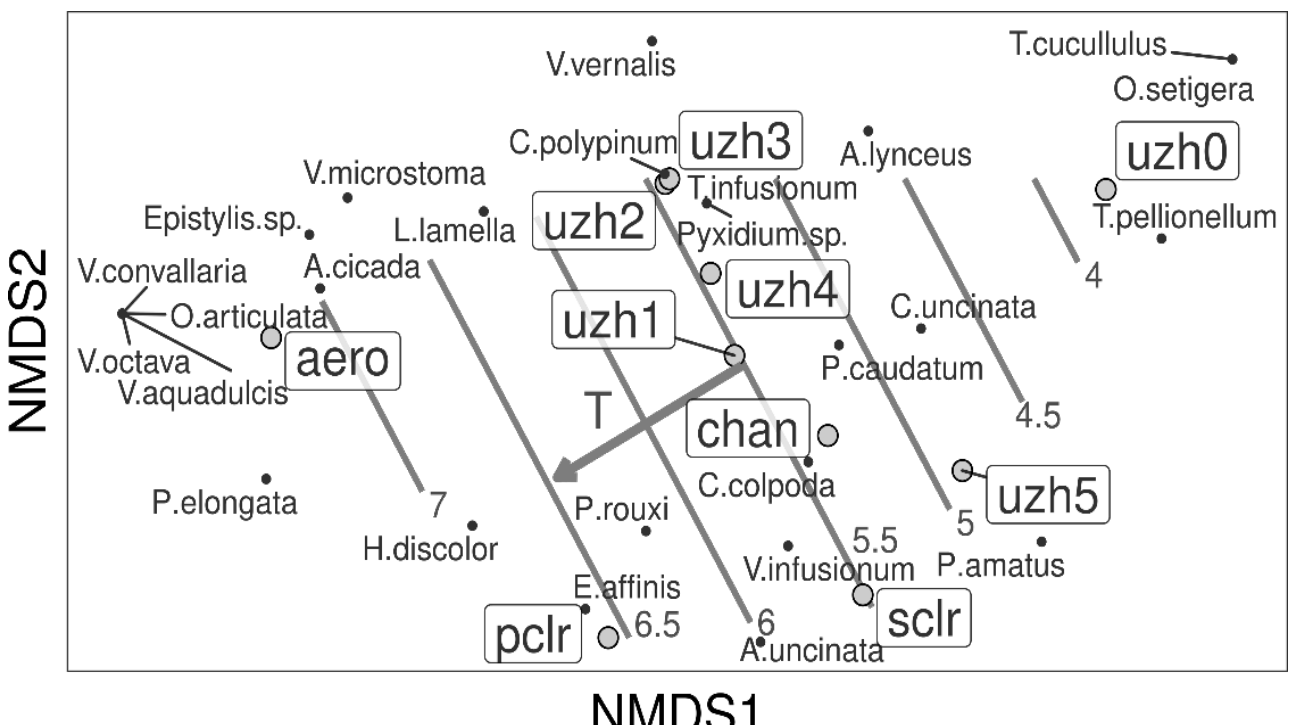

Fig. 3. Non-metric multidimensional scaling biplot of a Kulczynski distance matrix of Hellingertransformed data on the ciliates abundance with the gradient of dissolved temperature superimposed. The designations of the stations are the same as in Fig. 1.

However, the obtained data show that species oriented toward low concentrations of dissolved oxygen are better realized at higher temperatures. Nevertheless, in order to formulate more reliable conclusions regarding the environmental priorities of ciliates associated with a temperature gradient, more materials are needed, primarily collected at 
higher temperatures. On the basis of the acquired data, several statements can be made which are presented in the conclusions.

\section{Conclusions}

1. The study showed that the majority of the ciliate species, typical for bioreactors, are equally common at the stations of the Uzh River below wastewater discharges.

2. Moreover, contrary to the expectations, many species of infusoria, characteristic of the activated sludge, have reached maximum abundance precisely under the river conditions.

3. The ciliate assemblage in the oxygen gradient demonstrated a wide spectrum of ecological tolerance at the species level.

4. All these facts confirm that ciliates are very good indicators of environmental quality, provided that detailed information about their environmental priorities is available.

\section{References}

1. V. H. Smith, G. D. Tilman, J. C. Nekola, Environ. Pollut., 100, 1-3 (1999)

2. P. F. Strom, V.A. Matulewich, M. S. Finstein, Appl. Environ. Microbiol., 31 (1976)

3. S. A. Wakelin, M. J. Colloff, R. S. Kookana, Appl. Environ. Microbiol., 74, 9 (2008)

4. B. Gücker, M. Brauns, M. T. Pusch, J. N. Am. Benthol. Soc., 25 (2006)

5. J. L. Carter, V. H. Resh, M. J. Hannaford, M. J. Myers Macroinvertebrates as biotic indicators of environmental quality (Methods in Stream Ecology. Amsterdam: Academic Press, 2006)

6. I. A. Wright, B. C. Chessman, P. G. Fairweather, L. J. Benson, Aust. J. Ecol., 20 (1995)

7. EU Water Framework Directive 2000/60/EC. (2000)

8. D. Kominkova, D. Stransky, G. St'astna, J. Caletkova, J. Nabelkova, Z. Handova, Water Sci. Technol., 51, 2 (2005)

9. M. Gorzel, R. Kornijow, Ecohydrol. Hydrobiol., 7, 1 (2007)

10. M. A. Lewis, Ohio J. Sci., 86, 1 (1986)

11. P. Madoni, Hydrobiologia, 264, 3 (1993)

12. B. Spänhoff, R. Bischof, A. Böhme, S. Lorenz, K. Neumeister, A. Nöthlich, et al., Water Air Soil Pollut., 180 (2007)

13. J. O. Corliss, Acta Protozool., 41 (2002)

14. B. J. Finlay, G. F. Esteban, Biodivers Conserv., 7 (1998)

15. S. Yun-Fen, A. L. Buikema, jr., W. H. Yongue, jr., J. R. Pratt, J. Cairns jr., J. Protozool., 33 (1986)

16. D. H. Lynn, G. L. Gilron, J. Aquat. Ecosyst. Health, 1, 4 (1992)

17. J. R. Lawrence, G. D. W. Swerhone, L. I. Wassenaar, T.R. Neu, Can. J. Microbiol., 51 (2005)

18. J. D. Stout, Ecology, 37, 1 (1956)

19. H. Berger, W. Foissner Illustrated guide and ecological notes to ciliate indicator species (Protozoa, Ciliophora) in running waters, lakes, and sewage plants (Steinberg C, Editor. Handbuch Angewandte Limnologie. Ecomed Verlag, 2003)

20. S. Serrano, L. Arregui, B. Perez-Uz, P. Calvo, A. Guinea, Guidelines for the Identification of Ciliates in Wastewater Treatment Plants (IWA Publishing. wastewater-treatment-plants, London, 2008)

21. W. Foissner, H. Berger, Freshwater Biol., 35 (1996)

22. A. Warren, Bull. Br. Mus. Nat. Hist. (Zool.), 50, 1 (1986) 
23. A. Warren, Bull. Br. Mus. Nat. Hist. (Zool.), 52, 1 (1987)

24. P. Madoni, Water Res., 28 (1994)

25. R Core Team, R: A language and environment for statistical computing. R Foundation for Statistical Computing, Vienna, Austria (2017)

26. M. Maechler, P. Rousseeuw, A. Struyf, M. Hubert, K. Hornik, cluster: Cluster Analysis Basics and Extensions. R package version 2.0.6, (2017)

27. A. Kassambara, F. Mundt, factoextra: Extract and Visualize the Results of Multivariate Data Analyses. R package version 1.0.4. (2017)

28. J. Oksanen, F. G. Blanchet, M. Friendly, R. Kindt, P. Legendre, D. McGlinn, P. R. Minchin, R. B. O'Hara, G. L. Simpson, P. Solymos, M. Henry, H. Stevens, E. Szoecs, H. Wagner, vegan: Community Ecology Package. R package version 2.4-3 (2017)

29. H. Wickham, ggplot2: Elegant Graphics for Data Analysis (Springer-Verlag, New York, 2009)

30. Slowikowski, K. ggrepel: Repulsive Text and Label Geoms for 'ggplot2'. R package version $0.6 .5(2016)$

31. T. D. Hocking, directlabels: Direct Labels for Multicolor Plots. R package version 2017.03.31. (2017) 